\title{
THEORIES OF INNOVATION DEVELOPMENT: APPLICATION IN HIGHER MEDICAL EDUCATION
}

\author{
Alla Kulichenko \\ $\mathrm{PhD}$, Associate Professor, Zaporizhzhia State Medical University, Ukraine \\ e-mail: alla.kulichenko@gmail.com, orcid.org/0000-0003-1469-3816
}

\section{Summary}

The article deals with theories of innovation development, applied in higher medical education. The author synthesizes and systematizes the existing theoretical material on the issue. The study describes (i) diffusion of innovation theory which states that sometimes an idea or product evolves and spreads in a certain social system. As a result, people, being a part of the system, develop new ideas, behaviors, or products; (ii) evolutionary theories of innovations that consider innovation as a path-dependent process where it is developed through the interaction of different subjects and then tested in the market; (iii) linear models of innovations that mostly deal with the linked-chain model under which the innovation process occurs in conditions of uncertainty, rapid changes, and therefore can occur in several directions, and (iv) theory of innovation ecosystem which describes a complex of ties within the economic dynamics. These ties can be between subjects or formations, the main purpose of which is to provide the development of technologies and innovations.

Keywords: innovations, research and development, product, diffusion of innovation theory, evolutionary theories of innovations, linked-chain model, theory of innovation ecosystem.

\section{DOI: https://doi.org/10.23856/3860}

\section{Introduction}

The first 20 years of the $21^{\text {st }}$ century witnessed the rapid development of innovations and innovative activity in almost all spheres of human life. However, higher medical education and research attract more attention to this aspect. Because new technologies, methods of treatment, drugs, vaccines are key for a modern person, who aims at improving health and living longer. Thus, the need to understand the importance of innovation has led to recourse to many theoretical concepts that reveal the nature and mechanisms of this process, and to find strategies for its optimization.

It is significant to note that in the foreign scientific and pedagogical discourse, along with such terms as "concept", "theory", the term "model" is often used as a synonym. It sometimes contradicts the understanding of the model by domestic scientists. In our study, in terms of this concept prevalence in the scientific works of foreign authors, we are going to use the term "model" synonymously with the terms "theory" and "concept".

Besides, most concepts of innovation development and innovation emerged in the second half of the $20^{\text {th }}$ century in the field of economics, and only then were extended to other spheres of public life, including medical education. However, there are theoretical concepts focused on explaining the mechanism of innovation in social systems. Therefore, our research aims to highlight the most common theories of innovation, applied in higher medical education. We will describe diffusion of innovation theory, evolutionary theories of innovations, linear models of innovations, and theory of innovation ecosystem. 


\section{Diffusion of innovation theory}

In 1962 E. M. Rogers proposed diffusion of innovation theory. It explains how sometimes ideas or products accelerate and spread in a certain society. The outcome of such diffusion is that people, as members of the society, accommodate new ideas, modus operandi, or products. Adaptation implies that a person does anything else from before (e.g. purchasing or using a new item, learning a new behavior, etc.). Thus, a person must accept the mentioned things as something innovative (Diffusion of Innovation Theory, 2019). It is because of this, according to E. M. Rogers, diffusion is possible, as "the process by which an innovation is communicated through certain channels over time among the members of a social system" (Rogers, 1962: 5).

It is crucial to point out that the adaptation of innovations in the society cannot occur at the same time; rather, it is a development in which some individuals are more receptive to innovations than others. Note that human beings who perceive innovations quickly are significantly different from those who perceive these innovations more slowly. When advancing innovation to a focus group, it is exceptional to see its characteristics that will facilitate or impede the support of innovation. In this context, scientists distinguish the following categories of people based on their ability to adapt to innovation:

- innovators. These are persons who are eager to be the first to test innovations. They are ready for fresh ideas and concerned in them, prepared to risk. To interest this category, one doesn't need many efforts;

- early adopters, or persons who adapt quickly to innovation. They have leadership qualities and play key roles. They realize the importance of development and easy accept innovations. As a result, they don't need for extra information to make sure such changes are required but are attracted to new product management guides;

- early majority, or people who are quick to accept innovations. They can be seldom leaders but accept new ideas earlier than average citizens. Taking into account this fact, they usually want to see proof that innovation is working before they are ready to accept it. Successful examples and proof of innovation effectiveness can convince this category to innovate;

- late majority, or people who are slow to accept innovations. They are questioning changes. Besides, such people will accept innovations only after the majority tries them. Just success stories can convince this category to implement innovations;

- laggards, or people who do not keep up with innovations. They follow the traditions, and are old-fashioned, question changes, and are the most difficult category to innovate. Statistics, intimidation, and pressure from other people may convince them (Diffusion of Innovation Theory, 2019).

In the context of diffusion, adaptation of innovations is carried out during the following stages: 1) understanding of innovation necessity; 2) decision to admit (or refuse) innovation; 3) primary application of innovation for its future testing; 4) further use of innovation. Accordingly, it is possible to identify five principal elements that deal with innovation development. Moreover, each element promotes the need to innovate. So, there are the following items:

- relative advantage describes a condition when innovation is seen as superior to the thought, program, or item it replaces;

- competitiveness means how innovation meets the experience and demands of possible users;

- complexity is to what extent innovation can be difficult to interpret and/or apply;

- ability to test denotes the possibility to test innovation experimentally before a decision is made to adapt it; 
- the ability to identify a result deals with a situation when innovation shows visible outcomes (Diffusion of Innovation Theory, 2019).

However, the theory has many limitations. Thus, both theoretical provisions and classification of categories of persons based on their ability to adapt innovations are not applied to the field of health care, and therefore should be used with caution when adopting new attitudes or innovations in this field. Because in reality the theory application contributes to the implementation of new behavior, rather than stopping or preventing certain manifestations. Besides, the theory does not consider the individual capacity as well as the social assistance of a person to adopt something new. At the same time, in the field of health care, one can apply diffusion of innovation theory to expedite the adoption process of important programs, which are usually aimed at changing the attitude in the society. For instance, there is a strategy that deals with the problem of health care, and it must be promoted in society to accept it (refers to diffusion of innovation theory). Successful acceptance of a health protection program is the result of the focus group awareness and recognition of factors that affect the speed of their adoption (Rogers, 1962). In addition to health care, diffusion of innovation theory is applied in many fields, particularly in higher medical education.

\section{Evolutionary theories of innovations}

Evolutionary theories of innovation were developed in the field of economics (Nelson, Winter, 1982; Dossi et al., 1988). From these theories, innovation is considered as a path-dependent process in which it is developing through the interaction between different subjects and then is tested in the market. These interactions and market tests largely determine which of the developed products are successful, thereby influencing the future path of economic development. The work Models of Man (1982) by H. Simon on the theoretical foundations of decision-making and problem-solving has had a significant impact on the development of scientific discourse concerning innovations and the emergence of design thinking methods that use creativity to solve complex problems (Verganti, 2009).

According to K. Iwai, the essence of any evolutionary theory is Darwinism, i.e. the strongest survives and disseminates its distinctive features due to the increasing speed of reproduction. Concerning evolutionary theories, mechanism for the selection is developed through the difference in growth rates between high-profit and low-profit companies (or between lowprofit capital funds and low capital stocks) (Iwai, 2000).

Moreover, the author mainly argues that there are two ways that a company can follow to improve its technologies - innovation and imitation. The company can thrive in applying new and better technology through its research efforts. Also, it can increase its effectiveness by applying the more suitable technology of other companies. Then the technology development can be defined through the dynamic interaction of innovation and imitation (Iwai, 2000). So, we will consider the imitation process.

It is undeniable that technological information is not only social good that is freely accessible to businesses. However, it also cannot be only private. As K. Arrow states, "information in any productive way is bound to reveal it, at least in part" and "mobility of personnel among firms provides a way of spreading information the mobility of personnel between enterprises provides a way to disseminate information" (Arrow, 1962: 615). Even if the ownership belongs to proprietors of new technology, they can only create a part-time barrier, "since there are obviously enormous difficulties in defining in any sharp way an item of information and differentiating it from other similar-sounding items" (Arrow, 1962: 615). Thus, the new technology will 
be inevitably distributed to companies due to their imitation activities. And its secret is leaked faster, as more and more companies start to use this technology for production. There is always an element of the stripe effect in the dissemination of new ideas or things (Iwai, 2000).

When a limited amount of companies takes advantage of the best technology, imitation is subtle and user growth is slow. However, one imitation raises another and the spreading starts. The growth rate of the best technologies is accelerating until almost all enterprises adapt them. Then growth begins to decelerate, while the rate keeps growing until it absorbs all members of the industry. In the end, the best technology will prevail. Such a process of technological diffusion, in K. Iwai's opinion, resembles the evolutionary process of "Lamarckism" (Iwai, 2000), a theory of evolution based on the hypothesis that physical changes in organisms during their lives can be passed to offspring (Encyclopaedia Britannica, 2020).

The researcher notes, though, that achieving a long-term state of the industry, when every market participant has full access to the best technologies, is impossible because innovation or, according to J. Schumpeter, "new combination" (Schumpeter, 1961) hampers it (Iwai, 2000). Therefore, the function of innovation is to destroy the evolutionary trend that deals with static equilibrium.

Thus, we can state that evolutionary theories of innovations explain the process of their development in terms of the leading provisions of evolutionary theories by $\mathrm{Ch}$. Darwin and J.-B. Lamarck, which are applied in economics and management.

\section{Linear models of innovations}

A special place among many theories of innovation belongs to linear models of innovations and their alternatives, for example, the linked-chain model (Kline, Rosenberg, 1986).

Linear models of innovations were developed to streamline the innovation process conceptually, nevertheless, they distort the process somewhat, presenting it simply as an explicit linear process. According to this model, the development of innovations can be represented as the following algorithm (see Fig. 1).

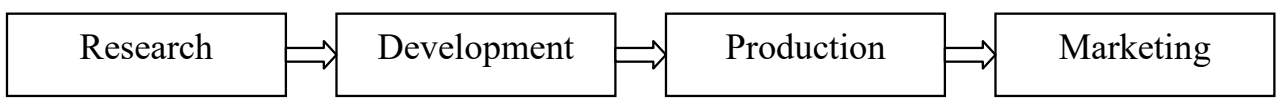

Figure 1. Innovation process from the position of a linear model

However, critics of these models emphasize the lack of feedback at different stages of innovation, as well as the lack of feedback from consumers of innovative products (Kline, Rosenberg, 1986: 286).

In this context, S. Kline and N. Rosenberg consider the linked-chain model more suitable. Its elements are presented in Fig. 2.

The authors of this model say that the innovation process starts in conditions of uncertainty, rapid changes, and therefore can occur in several directions. Moreover, researchers identify the main direction of innovation development, so-called "central chain of innovation", which begins with a project, goes through the stages of development, production, and marketing. It deals with stages that describe the linear models. At the same time, there are other ways of feedback, which indicate the directions of cooperation with stakeholders in the process of designing, developing, producing, and disseminating innovations, taking into account the needs of the market and the individual needs of consumers. In this regard, S. Kline and N. Rosenberg 
note that market needs can only be met through solving technological problems. Besides, they add that the opposition between "market engines" and "technology engines" is somewhat artificial, because any market requirement, being the innovation cycle, eventually leads to the development of new projects, and each new successful project results in the emergence of new market environment (Kline, Rosenberg, 1986).

\begin{tabular}{|c|c|c|c|c|}
\hline \multicolumn{4}{|c|}{ Scientific research } \\
\hline $\begin{array}{c}\text { Potential } \\
\text { market }\end{array}$ & $\begin{array}{c}\text { Invention and/ } \\
\text { or } \\
\text { development } \\
\text { of an } \\
\text { analytical } \\
\text { project }\end{array}$ & $\begin{array}{c}\text { Detailed } \\
\text { project and } \\
\text { testing }\end{array}$ & $\begin{array}{c}\text { Reproject and } \\
\text { production }\end{array}$ & $\begin{array}{c}\text { Distribution } \\
\text { and market }\end{array}$ \\
& & & \\
\hline
\end{tabular}

Figure 2. Elements of the linked-chain model (Kline, Rosenberg, 1986: 289)

So, in addition to the central chain, the linked-chain model assumes the presence of:

- numerous feedbacks which link and coordinate innovation (research and development) with manufacturing and marketing;

- side links with research throughout the central chain;

- long-term large-scale researches to create reserve innovations;

- potentiation of completely new products or processes from research;

- enrichment of the scientific field with innovative products (Kline, Rosenberg, 1986: 303).

\section{Theory of innovation ecosystem}

Referring to the theory of innovation ecosystem, we can assume that there is a certain conceptual analogy between the innovation ecosystem and the biological ecosystem, which can prevail in nature. Thus, the biological ecosystem includes both all living organisms (biotic factors) in the environment and its physical environment (abiotic factors). They function as a whole unit. The biological ecosystem may have one or more states of equilibrium, where there is a comparatively stable set of conditions for maintaining the population or exchanging nutrients at certain levels. The biological ecosystem has definite functional characteristics that regulate changes or maintain the stability of the desired state of equilibrium. In the biological ecosystem, the state of equilibrium is described by modeling the energy dynamics of ecosystem operations. In this context, energy presents a predator-prey relationship and plants transmit energy; calories are burned by consuming a prey, thus transferring the energy of the prey to the predator, and when the plants die and decompose, their energy is transferred to the soil, where it is again consumed by other plants. So, energy dynamics is a complex function and the ecosystem can be considered as a whole unit because each part of the ecosystem functionally affects the other one (The Scale Project, 2005).

Summarizing the previous statement, we can note that the biological ecosystem is a complex set of relationships between living resources, habitat, and its inhabitants. As for its functional purpose, it may maintain a stable equilibrium. 
Instead, the innovation ecosystem describes the economic dynamics of a set of relationships between subjects or formations. Their functional purpose is to enable the development of technology and innovations. In this connection, the subjects can be both material resources (funds, equipment, resources, etc.) and human capital (students, teachers, non-academic staff, industry researchers, industry representatives, etc.), which constitute the institutional structures involved in the ecosystem (e.g. universities, engineering colleges, business schools, business firms, venture capitalists, university research institutes, federal or industrial quality centers, as well as state and/or local economic development and business promotion organizations, financial agencies, politicians, etc.).

The innovation ecosystem includes the knowledge economy that concerns basic research and the commercial economy that regulates the use of market mechanisms. These economies are interconnected because the resources invested in the knowledge economy must come from the commercial sector. This statement means that government investment in innovation (research and development) is ultimately derived from tax revenues. However, according to D. Jackson, to stimulate innovative activity, it is necessary to distinguish initiatives that regulate the knowledge economy from financial stimuli that regulate the commercial economy (Jackson, 2011).

Thus, one of the important characteristics of the innovation ecosystem is the fact that the resources present in the knowledge economy are related to the resources developed by the commercial economy, usually as a part of the income in the commercial economy. Another feature is that formations within the innovation ecosystem are either geographically localized or strategically linked to focus on the development of a specific technology (Jackson, 2011). The best-known example of the geographically localized ecosystem is Silicon Valley, while examples of strategically linked ecosystems include Innovation Ecosystem Development Initiative (the US Department of Energy), which focuses on accelerating the introduction of energy innovations, and the European Innovation Initiative's Digital Ecosystem technologies, which aimed at business system creation that based on information and communication technologies (Williams, Lewis, 2010; Jackson, 2011).

It is worth to mention that the outlined strategic initiatives at the international and national levels are illustrative, but not isolated examples, as innovative ecosystems can be created to solve any problem.

It is worth noting that the innovation ecosystem is prosperous and healthy when resources invested in the knowledge economy (through private, public, or direct investment in the business) are subsequently replenished by increased income in the commercial economy (Jackson, 2011).

\section{Conclusions and suggestions}

After reviewing theories of innovation development, applied in higher medical education, we can conclude that the most common ones are diffusion of innovation theory; evolutionary theories of innovations; linear model of innovations; theory of innovation ecosystem.

Diffusion of innovation theory was proposed by E. M. Rogers in the 1960s. It states that sometimes an idea or product evolves and spreads in a certain social system. The outcome of such diffusion points out that people, being a unit of the system, develop new ideas, behaviors, or products.

Evolutionary theories of innovations consider innovation as a path-dependent process where it is developed through the interaction of different subjects and then tested in the market. 
These theories explain the process of their development in terms of the leading provisions of Darwinism and Lamarckism.

Linear models of innovations mostly deal with the linked-chain model under which the innovation process occurs in conditions of uncertainty, rapid change, and therefore can occur in several directions.

Theory of innovation ecosystem describes which describes a complex of ties within the economic dynamics. These ties can be between subjects or formations, the main purpose of which is to provide the development of technologies and innovations.

As for the prospects of future researches, we will cover the conceptual bases of comparative and pedagogical researches relating to innovative activity in higher medical education.

\section{References}

Arrow, K. J. (1962). Economic Welfare and the Allocation of Resources for Inventions. In Nelson, $R$. R. (Ed.), The Role and Direction of Inventive Activity (pp. 609-626). Princeton: Princeton University Press. [in English].

Diffusion of Innovation Theory. (2019). [Electronic resource]. Retrieved from: https:// sphweb.bumc.bu.edu/otlt/MPH-Modules/SB/BehavioralChangeTheories/BehavioralChangeTheories4.html. [in English].

Dossi, G., Freeman, G., Nelson, R., Silverberg, G., Soete, L. (Eds.) (1988). Technical Change and Economic Theory. London. [in English].

Encyclopaedia Britannica. Lamarckism. (2020). [Electronic resource]. Retrieved from: https://www.britannica.com/science/Lamarckism. [in English].

Iwai, K. (2000). A Contribution to the Evolutionary Theory of Innovation, Imitation and Growth. Journal of Economic Behavior and Organization, 43 (2), 167-198. [in English].

Jackson, D. J. (2011). What is an Innovation Ecosystem? National Science Foundation, Arlington, VA. [Electronic resource]. Retrieved from: https://erc-assoc.org/sites/default/files/topics/ policy_studies/DJackson_Innovation\%20Ecosystem_03-15-11.pdf. [in English].

Kline, $\bar{S}$., \& Rosenberg, $\bar{N}$. (1986). An Overview of Innovation. [Electronic resource]. Retrieved from: http://dec.ec.unipg.it/ fabrizio.pompei/KlineRosenberg(1986).pdf. [in English].

Nelson, R., Winter, S. (1982). An Evolutionary Theory of Economic Change. Harvard University Press: Cambridge, MA. [in English].

Rogers, E. M. (1962). Diffusion of Innovations. New York. [in English].

Schumpeter, J. A. (1961). The Theory of Economic Development. Oxford: Oxford University Press. [in English].

The Scale Project. (2005). [Electronic resource]. Retrieved from http://www.sustainablescale.org/ home.asp. [in English].

Verganti, R. (2009). Design-Driven Innovation: Changing the Rules of Competition by Radically Innovating What Things Mean. Boston, MA: Harvard Business Press. [in English].

Williams, J. E., Lewis, Jr. (2010). Post Graduation Status of National Science Foundation Engineering Research Centers. Report of a Survey of Graduated ERCs, Prepared for the National Science Foundation by SciTech Communications LLC, January. [in English]. 